\title{
Superplastic deformation of a relatively coarse- grained AZ80 magnesium alloy
}

\author{
Wang Zhongjun *, Wang Zhaojing, Zhu Jing \\ School of Materials and Metallurgy, University of Science and Technology Liaoning, \\ 185 Qianshan Zhong Road, Anshan 114051, P.R. China \\ *Corresponding author. Tel: (+86) 412 5929535; Fax: (+86) 412 5828165; E-mail: zhongjunwang@ 126.com
}

Received: 22 Dec 2010, Revised: 22 Feb 2011 and Accepted: 28 Feb 2011

\section{ABSTRACT}

Superplastic deformation behaviors of a relatively coarse-grained AZ80 magnesium alloy sheet have been investigated at temperature ranging from 350 to $430{ }^{\circ} \mathrm{C}$ and at the strain rates ranging from $1.31 \times 10^{-4}$ to $1.31 \times 10^{-2} \mathrm{~s}^{-1}$ by uniaxial tensile tests. Superplasticity with the maximum elongation to failure of $239 \%$ was obtained at $430{ }^{\circ} \mathrm{C}$ and the strain rate of $6.56 \times 10^{-4}$ $\mathrm{s}^{-1}$ and its strain rate sensitivity exponent, the value of $\mathrm{m}$ is high up to 0.49 . Fine interior dynamic recrystallized (DRX) grains distributed along primary grains were observed during superplastic deformation, but primary grains were not found significantly grown up. In addition, micro-cavities and their coalescences were also observed in the superplastic deformation of the relatively coarse-grained AZ80 magnesium alloy sheet. Grain boundary sliding (GBS) was considered to be the main deformation mechanism during the superplastic deformation. Dislocation creep controlled by atom diffusion through interior DRX and primary grains is suggested mainly to accommodate the GBS in superplastic deformation. Copyright $\odot 2011$ VBRI press.

Keywords: Superplasticity; relatively coarse-grain; GBS, DRX; AZ80 magnesium alloy.
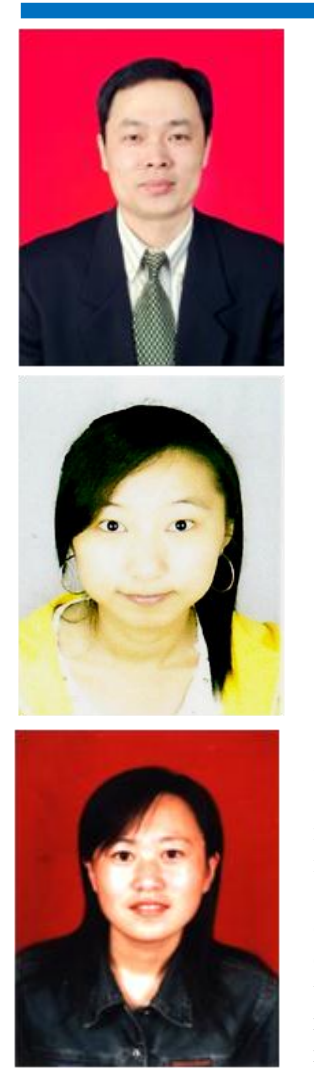

Zhu Jing is a Lecture, who had graduated and obtained master degree from University of Science and Technology Liaoning in 2007. She is very good in experimental teaching on metal materials to undergraduate students. At present, she is working scientific research on the developing advanced magnesium alloy containing rare earth element with two undergraduate students. She has published two research papers in English and Chinese, respectively.

\section{Introduction}

Magnesium is the lightest constructional metal on earth; the $1.74 \mathrm{~g} / \mathrm{cm}^{3}$ density makes magnesium $35 \%$ lighter than aluminum $\left(2.70 \mathrm{~g} / \mathrm{cm}^{3}\right)$, and $78 \%$ lighter than steel $(7.85$ $\mathrm{g} / \mathrm{cm}^{3}$ ). In addition, magnesium has better damping characteristics than aluminum. However, magnesium alloys have poor formability and limited plasicity at room temperature because of their H.C.P. crystal structure with limited operative slip systems at room temperature which restrict their application [1-3].

Superplastic forming has been proved to play an important role in fabricating complicated parts. It is well known that superplastic deformation occur when the grain size is homogeneously distributed, equiaxed and extremely fine, typically no more than $10 \mu \mathrm{m}$. In order to reduce grain size of magnesium alloys, some thermal deformation processings have been used, for example, equal channel angular extrusion (ECAE) and hot rolling et al [4-5], which must increase the productive costing of parts. Many other investigations observed superplasticity of AZ31 magnesium alloy with fine grains [6-7]. However, few of study on superplastic behavior of coarse-grained magnesium have been found $[\mathbf{8}]$. For the lower productive cost of wrought magnesium alloy parts, the research of superplastic forming behaviors of coarse-grained magnesium alloy is of great interests to science and technology workers.

In this study, Superplastic behavior and microstructure evolutions of a relatively coarse-grained $(\approx 35 \mu \mathrm{m})$ AZ80 magnesium alloy sheet have been investigated by uniaxial 
tensile tests, and the superplastice mechanism was discussed, which can lead to develop a good and low costing productive processing of plastic thermal deformation.

\section{Experimental}

The material used in the study was an extruded AZ80 (Mg8.2 wt. \% Al-0.3 wt. \% Zn-0.6wt. \% Mn) magnesium alloy sheet. The as-received sheet had a mean grain of $\approx 35 \mu \mathrm{m}$ after homogenization treatment of $380{ }^{\circ} \mathrm{C} \times 2 \mathrm{~h}$, which was supplied by Yingkou galactic magnesium-aluminum alloy limited corporation in Liaoning province of P.R. China.

Tensile specimens were machined directly from the asreceived sheet with their tensile axes parallel to the extruded direction. The tensile specimens had a gauge length of $10 \mathrm{~mm}$, a width of $5 \mathrm{~mm}$, and a thickness of 5 $\mathrm{mm}$. Constant velocity tensile tests were carried out at temperatures ranging from 350 to $430{ }^{\circ} \mathrm{C}$ and at initial strain rates ranging from $1.31 \times 10^{-4}$ to $1.31 \times 10^{-2} \mathrm{~s}^{-1}$ in air on a MTS-810 tensile machine equipped with electrical resistance heating chamber. The specimens required $30 \mathrm{~min}$ to equilibrate at the tested temperature prior to initiation of straining. The temperature variation during the tensile tests was no more than $\pm 1{ }^{\circ} \mathrm{C}$.

Microstructures of the extruded AZ80 magnesium alloys before and after the tensile test were observed by a HAL-100 optical microscopy. Via conventional grinding and polishing, specimens were etched using a mixed solution of $5 \mathrm{~g}$ carbazotic acid, $5 \mathrm{ml}$ acetic acid, $1 \mathrm{ml}$ nitric acid and $100 \mathrm{ml}$ water for microstructure observation, which were all chemically pure reagents and supplied by Shenyang chemical materials limited corporation in Liaoning province of P.R. China.

\section{Results and discussion}

Untested and fractured tensile specimens under various strain rates are shown in Fig. 1, where a maximum elongation of $239 \%$ was obtained at $430^{\circ} \mathrm{C}$ and $6.56 \times 10^{-}$ ${ }^{4} \mathrm{~s}^{-1}$. The tensile deformation was apparently relatively uniform and no visible necking was observed around the fracture when strain rate was lower than $1.31 \times 10^{-2} \mathrm{~s}^{-1}$, which demonstrated that the superplastic deformation was homogeneous and the necking was restrained at lower strain rate.

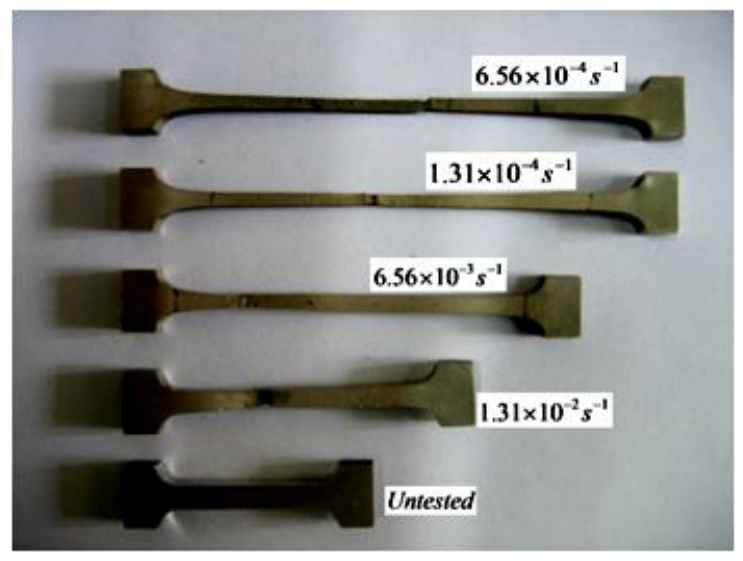

Fig. 2. Untested and fractured tensile specimens of AZ80 magnesium alloy sheets under various strain rates at $430{ }^{\circ} \mathrm{C}$.
Fig. 2 (a-d) shows the true stress-strain curves obtained at various strain rates with the stable temperature of 350 , 380,410 and $430{ }^{\circ} \mathrm{C}$, respectively. It is shown that all of the curve exhibit obvious strain hardening peak when the strain value is lower than 0.1. From Fig. 2 we can also find that the stress peak decreases significantly with increasing temperature, which is related to the strain softening of the material due to the activation of non-basal slip systems. At the meanwhile, steady and slow reduction of flow stress was found when the strain rate is lower than $6.56 \times 10^{-3} \mathrm{~s}^{-1}$ besides the condition of $6.56 \times 10^{-4} \mathrm{~s}^{-1}$ at $350{ }^{\circ} \mathrm{C}$. The reason for it is probably that dynamic recrystallization (DRX) occurred during thermal deformation at lower strain rate.
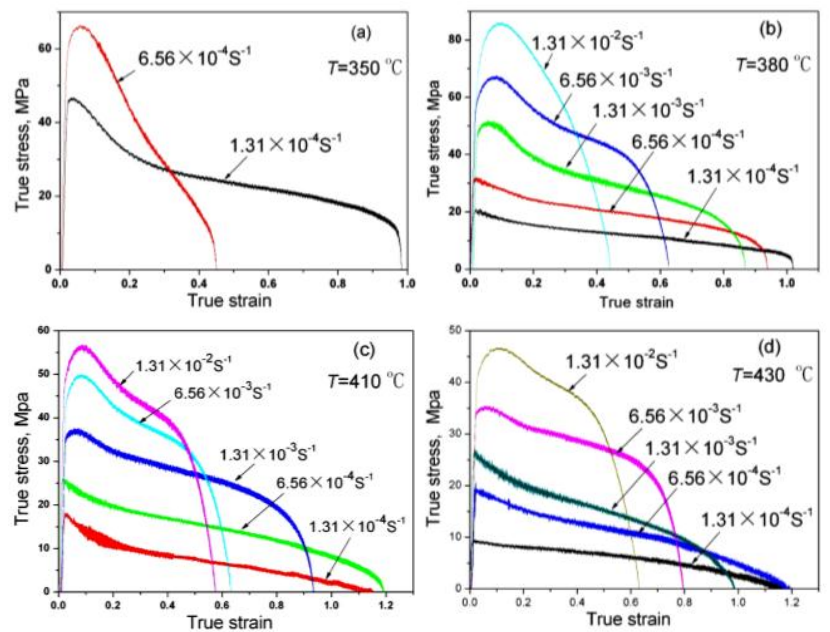

Fig. 2. True strain-stress curves of $A Z 80$ alloy sheets under various strain rates. (a) $350{ }^{\circ} \mathrm{C}$; (b) $380{ }^{\circ} \mathrm{C}$; (c) $410{ }^{\circ} \mathrm{C}$; (d) $430{ }^{\circ} \mathrm{C}$.

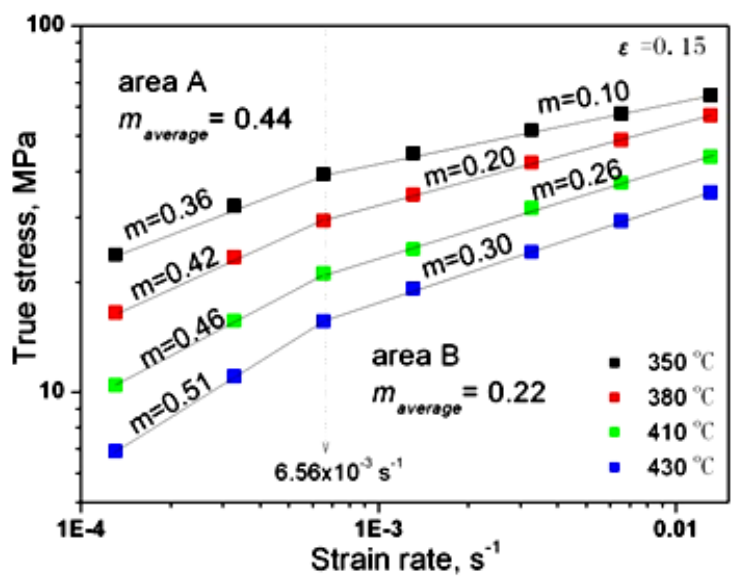

Fig. 3. Variation of flow stress as a function of strain rate.

The variation of flow stress at a fixed strain of 0.15 as a function of strain rate is plotted in Fig. 3. The strain of 0.15 was selected so that the change of grain size during initial superplastic deformation stage was negligible [9]. The strain rate sensitivity, $\mathrm{m}$, defined as the slope of the double logarithmic plot of flow stress verse strain rate, is apparently distinct at different temperature. It has demonstrated that the flow stress increased with increasing strain rate, and exhibited two areas of A and B. An average 
$\mathrm{m}$ value of 0.44 was obtained in $\mathrm{A}$ area (strain rates are lower than $6.56 \times 10-3 \mathrm{~s}-1)$. This relatively high $\mathrm{m}$ value demonstrated that grain boundary sliding (GBS) could be a primary deformation mechanism [10]. Meanwhile, the average $m$ value was decreased to 0.22 in $B$ area, which might be due to the dislocation creep process [11]. Furthermore, we can also find that the $m$ value was increased with increasing temperature.

The variation of elongation to failure as a function of strain rate and temperature is shown in Fig. 4 (a, b, respectively). It is demonstrated from Fig. 4 that the tensile elongation depended on strain rate and temperature. The tensile elongation decreased rapidly with the increase in strain rate ranging from $6.56 \times 10^{-3}$ to $1.31 \times 10^{-2} \mathrm{~s}^{-1}$ and with the decrease of temperature from 430 to $350{ }^{\circ} \mathrm{C}$. The elongation remained the lowest elongation to failure because of the lower $m$ value of 0.10 and 0.20 at 350 and $380{ }^{\circ} \mathrm{C}$, respectively, at strain rate higher more than $6.56 \times$ $10^{-3} \mathrm{~s}^{-1}$. For the AZ80 magnesium alloy sheet, two superplastic elongations to failure both above $200 \%$ were obtained at temperatures of 410 to $430{ }^{\circ} \mathrm{C}$ and at strain rates of $1.31 \times 10^{-4} \mathrm{~s}^{-1}$ to $6.56 \times 10^{-4} \mathrm{~s}^{-1}$, respectively. The maximum elongation to failure of $239 \%$ was obtained at $430{ }^{\circ} \mathrm{C}$ and $6.56 \times 10^{-4} \mathrm{~s}^{-1}$ (Fig. $4 \mathrm{~b}$ ), corresponding to a high $\mathrm{m}$ value of 0.51 .
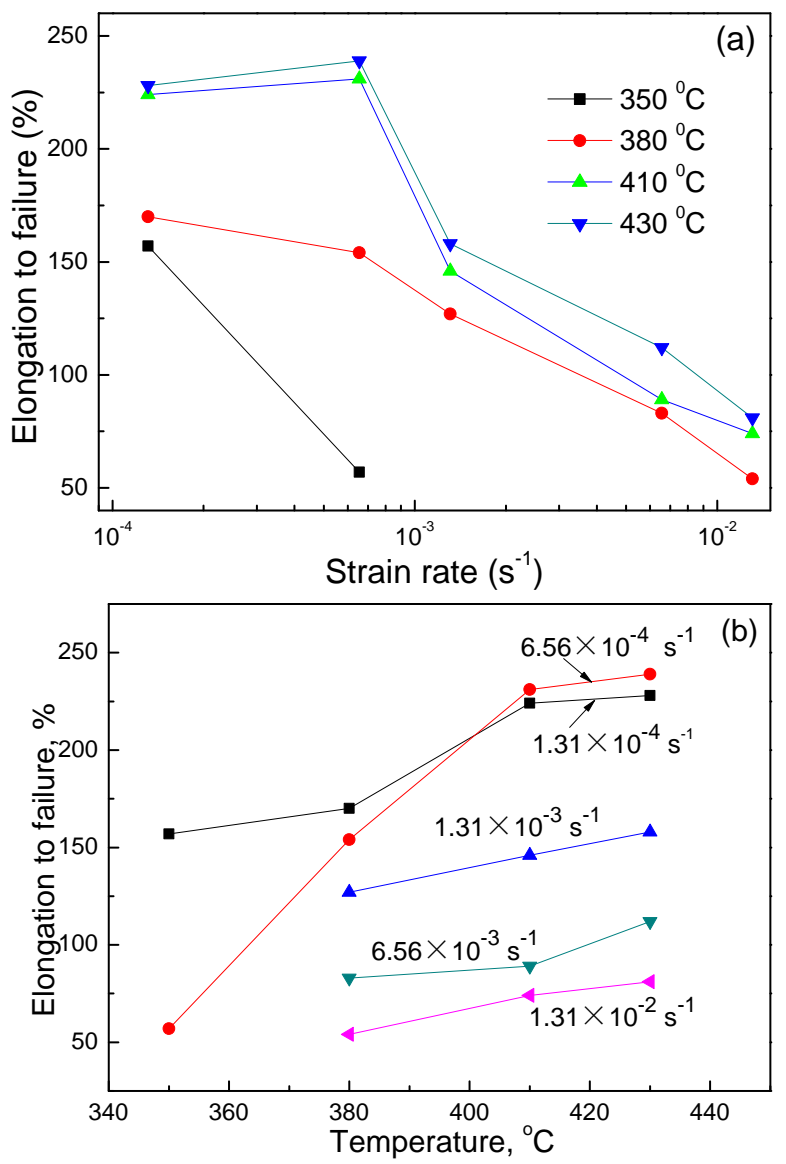

Fig. 4. Variation of elongation to failure as a function of strain rate and temperature (a) as a function of strain rate; (b) as a function of temperature.

In order to understand the mechanism during the superplastic process, the superplastic deformation activation energy $\mathrm{Q}$ was calculated under constant strain rate by the following equation:

$$
Q=\left.n R \frac{\partial(\ln \sigma)}{\partial(1 / T)}\right|_{\dot{\varepsilon}}
$$

where, $\sigma$ is the flow stress, $n$ is the stress exponent ( $n=$ $1 / m), \mathrm{R}$ is the gas constant $(\mathrm{R}=8.314 \mathrm{~J} / \mathrm{K}), \mathrm{T}$ is the absolute temperature and $(\ln \sigma) /(1 / \mathrm{T})$ was estimated from the slope of the curve in Fig. 5. It can be seen in Fig. 5 that the slopes of curves increased with decreasing strain rates, which stated that the activation energy at a higher strain rate has changing scales. The activation energy was determined to be from 96 to $210 \mathrm{~kJ} \cdot \mathrm{mol}^{-1}$, which was not similar to that for activation energy for lattice diffusion $\left(134 \mathrm{~kJ} \cdot \mathrm{mol}^{-1}\right)$ and but higher than that of grain boundary self-diffusion $\left(75 \mathrm{~kJ} \cdot \mathrm{mol}^{-1}\right)$ of magnesium alloys, respectively. Our pre-work reported that the activation energy for creep in magnesium alloy showed the temperature dependence [12]. The higher activation energy (higher than $134 \mathrm{~kJ} \cdot \mathrm{mol}^{-1}$ ) at higher temperatures is believed to be that the deformation behavior is not controlled by lattice diffusion but by cross slip of screw dislocations from the basal to the prismatic planes. The activation energy $\left(210 \mathrm{~kJ} \cdot \mathrm{mol}^{-1}\right)$ obtained at $430{ }^{\circ} \mathrm{C}$ and $1.31 \times 10^{-4} \mathrm{~s}^{-1}$ demonstrated that dislocation creep may play a critical role of maintaining the superplastic deformation process.

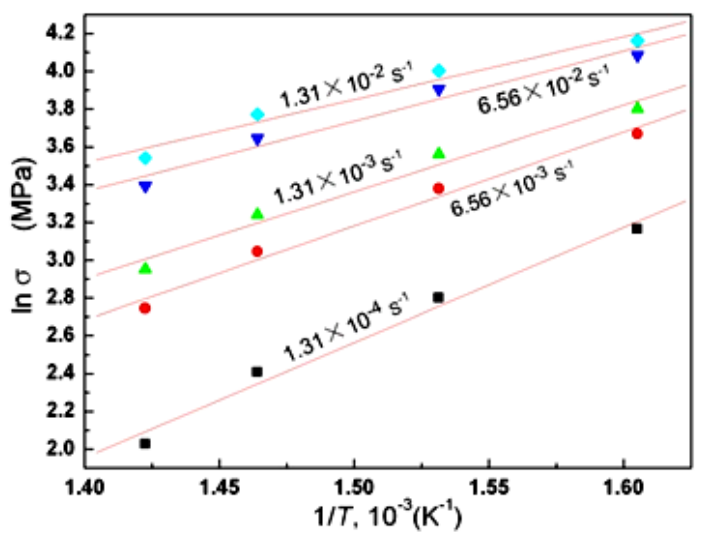

Fig. 5. Activation energy curves of $\ln$ (flow stress) vs. $1 / T$ in the superplastic deformation of the AZ80 magnesium alloy.

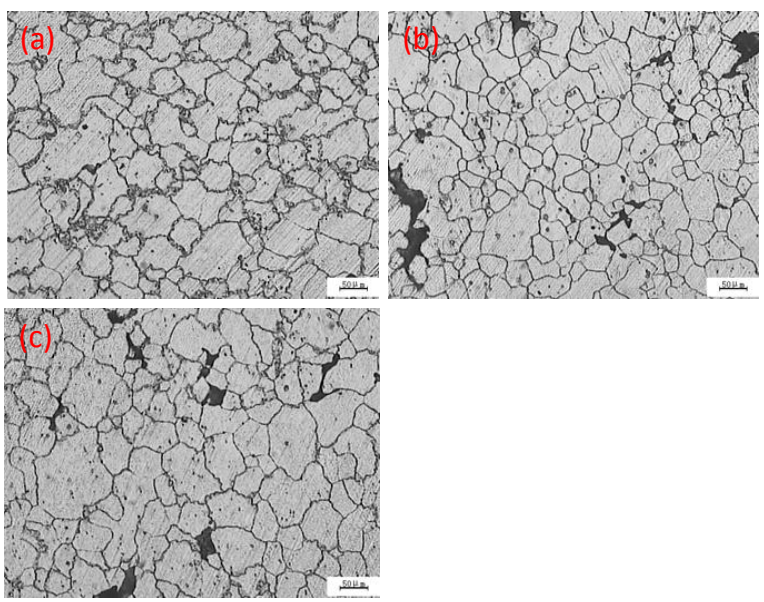

Fig. 6. Microstructures near fracture tip for the specimens deformed at the strain rate of $6.56 \times 10^{-3} \mathrm{~s}^{-1}$ and at different temperature (a) $380{ }^{\circ} \mathrm{C}$; (b) $410{ }^{\circ} \mathrm{C}$; (c) $430{ }^{\circ} \mathrm{C}$. 
Fig. 6 (a-c) shows the microstructure near fracture tip for the specimens deformed at the strain rate of $6.56 \times 10^{-3}$ $\mathrm{s}^{-1}$ and at different temperature of 380,410 and $430^{\circ} \mathrm{C}$, respectively. From Fig. 6 (a) we can see that lots of dynamic recrystallized (DRX) grains distributed along primary grain boundaries are fine. In addition, some relatively coarse DRX grains are found, and their size is increasing with increasing deformation temperature (Fig. 6 b-c). What' more, the cavity appearance near the fracture tip when the tensile temperature is high up to 410 and $430^{\circ} \mathrm{C}$.

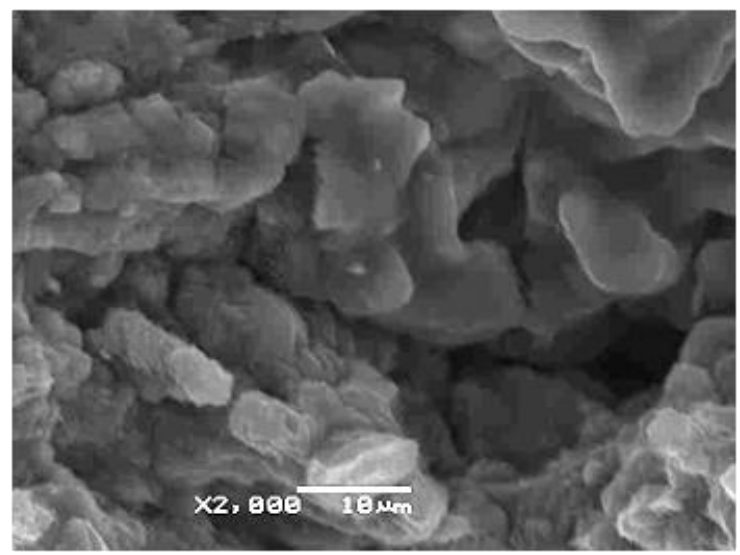

Fig. 7. Tensile fracture surfaces obtained at $430{ }^{\circ} \mathrm{C}$ and at a strain rate of $6.56 \times 10^{-4} \mathrm{~s}^{-1}$.

The tensile fracture surfaces of AZ80 sheet at $430^{\circ} \mathrm{C}$ and at a strain rate of $6.56 \times 10^{-4} \mathrm{~s}^{-1}$ is shown in Fig. 7. It can be clearly observed from Fig. 7 that the specimen is basically fractured intergranularly. The fracture manner is obviously the cleavage between grain boundaries and there is no trace of tearing fracture. In addition, some of fine DRX grains can be also found. Thus, it can be deduced that primary or DRX grain boundary slip (GBS) is the main deformation mechanism.

\section{Conclusion}

Superplastic deformation behaviors of a relatively coarsegrained $(\approx 35 \mu \mathrm{m})$ AZ80 magnesium alloy sheet have been investigated by uniaxial tensile tests, some conclusions can be drawn as followed:

i. Superplasticity with the maximum elongation to failure of $239 \%$ was obtained at $430{ }^{\circ} \mathrm{C}$ and the strain rate of $6.56 \times 10^{-4} \mathrm{~s}^{-1}$ and its strain rate sensitivity exponent, the value of $\mathrm{m}$ is high up to 0.49 .

ii. Fine interior dynamic recrystallized (DRX) grains distributed along primary grains were observed during superplastic deformation, but primary grains were not found significantly grown up. Micro-cavities and their coalescences were also observed in the superplastic deformation of the relatively coarse-grained AZ80 magnesium alloy sheet.

iii. Fine DRX and primary grain boundary sliding (GBS) was considered to be the main deformation mechanism during the superplastic deformation. Dislocation creep controlled by atom diffusion through interior DRX and primary grains is suggested mainly to accommodate the GBS in superplastic deformation.

\begin{abstract}
Acknowledgement
The authors acknowledge the support of the key lab of material forming and microstructure \& properties control of education ministry of Liaoning province in China, University science study project fund of education ministry of Liaoning province in China, also appreciate the support of college student science study project (No.6-2010) of university of science and technology Liaoning.
\end{abstract}

\section{References}

1. Fadi, K.A.; Marwan, K.K. Journal of Materials Engineering and Performance 2007, 16, 192. DOI: $10.1007 / \mathrm{s} 11665-007-9031-5$

2. Wang, Z.J.; Jia, W.P.; Cui, J.Z. Journal of Rare Earths 2007, 25, 744. DOI: $\underline{10.1016 / \mathrm{S} 1002-0721(08) 60019-8}$

3. Wang, Z.J.; Yang, Q.X.; Qiao, J. Trans. Nonferrous Metals Society of China 2010, 20, s567. DOI: $\underline{10.1016 / \mathrm{S} 1003-6326(10) 60539-0}$

4. Yan, H.; Chen, R.S.; Han, E.H. Science in China Series (E) 2009, 52, 166. DOI: $10.1007 / \mathrm{s} 11431-008-0293-4$

5. Wang, P.; Wu, L.H.; Guan, S.K. Trans. Nonferrous Metals Society of China 2010, 20, s527. DOI: $10.1016 / \mathrm{S} 1003-6326(10) 60532-8$

6. Feng, X.M.; Al, T.T. Trans. Nonferrous Metals Society of China 2009, 19, 293. DOI: $10.1016 / \mathrm{S} 1003-6326(08) 60267-8$

7. Panicker, R.; Chokshi, A.H.; Mishra, R.K.; Verma, R.; Krajewski, P.E. Acta Materialia 2009, 57, 3683 DOI: $10.1016 /$ j.actamat.2009.04.011

8. Wu, X.; Liu, Y. Scripta Materialia, 2002, 46, 269. DOI: 10.1016/S1359-6462(01)01234-9

9. Kim, W.J.; Kim, M.J.; Wang, J.Y. Material. Science and Engineering: A 2009, 527, 323. DOI: $10.1016 /$ j.msea.2009.08.064

10. Clarisse, L.; Bataille, A.; Pennec, Y.; Crampon, J.; Duclos, R. Ceramics International 1999, 25, 389. DOI: $10.1016 / \mathrm{S} 0272-8842(98) 00044-3$

11. Wang, Q.D.; Wei, Y.H.; Chino, Y.; Mabuchi, M. Rare Metal 2008, 27,46 . DOI: $10.1016 / \mathrm{S} 1001-0521(08) 60028-5$

12. Wang, Z.J.; Zhu, J.; Wang, Z.J.; Kang, B.H. Advanced Materials Letters 2011, $x x$, $\mathrm{xxx}$ (accepted). DOI: $10.5185 /$ amlett.2011.xxxx 


\section{AdVANCEd MATERIALS Letters}

\section{Publish your article in this journal}

ADVANCED MATERIALS Letters is an international journal published quarterly. The journal is intended to provide top-quality peer-reviewed research papers in the fascinating field of materials science particularly in the area of structure, synthesis and processing, characterization, advanced-state properties, and applications of materials. All articles are indexed on various databases including $\underline{\mathrm{DOAJ}}$ and are available for download for free. The manuscript management system is completely electronic and has fast and fair peer-review process. The journal includes review articles, research articles, notes, letter to editor and short communications.

Submit your manuscript: http://amlett.com/submitanarticle.php 